\title{
Computer Aided Methodology for Design of Robots in Construction Industry
Applications
}

\author{
C. Balaguer ${ }^{1}$ \\ E. Gambao \\ A. Barrientos \\ R. Saltarén \\ Departamento de Automática, Ingeniería Electrónica e Informática Industrial \\ Polytechnic University of Madrid \\ José Gutierrez Abascal, 2. E-28006 Madrid, Spain. \\ Email: balaguer@ing.uc3m.es
}

\begin{abstract}
New large range robots with hydraulic actuators play a key role in the automation of several important construction tasks and its demand is increasing nowadays. However the steps for design this type of robots are not structured today, and it is performed in an individual way. This paper presents a new computer aided methodology for design of robots in construction industry applications. This methodology is based on the 3D kinematics CAD toolbox for robot simulation TOROS [1] and software modules linked to 3D dynamics simulation package ADAMS [2].

This methodology has been applied in an iterative way for design of the large range on site assembly ROCCO robot [3] (for wall erection using big blocks) and for a metallic structure inspection robot that is under development now.
\end{abstract}

\section{Introduction}

The application of new automatic systems for the construction industry on site environment is increasing nowadays. In the next future some of these systems will be mainly intelligent large range robot manipulators. These robots will work in a set of new on site applications, such as wall erection, material transport, interior finish work, concrete distribution, etc. These applications demands new robots configurations mainly driven by hydraulic actuators with a high load capacity [4]. Nevertheless, unlike the electric actuators, control of hydraulic actuators is a difficult problem [5].

Nowadays only a few of these kind of manipulators have been designed and built: EMIR [6], LSM [7], and
ROCCO. These robots have been individually developed without a common methodology. A carefully design that avoids very expensive prototypes without economical justification is very important. The complete design of the robots, including kinematics configuration, actuator and materials selection and dynamic analysis is a tough task
not systematised and not structured.

When the robot's dimensions grow the dynamic behaviour becomes worse, the natural frequency is lower (sometimes less than $2 \mathrm{~Hz}$ ) and other difficulties such as structural vibrations and deflections appear. Moreover, these kind of robots are highly nonlinear systems. All of these difficulties must be taken into account during the robot development to reach the required performance specifications. The adequate mechanical design is a very critical aspect that determine the succeed of the system avoiding positioning errors, minimising structural deflections and reducing the cycle time.

Large range robots specifically development for construction industry must fulfil several performance requirements to work in real site conditions, which, by fact, exceed what is required from standard industrial robots [8]. The robot must been light and dextrous enough to work in real site assembly conditions. Moreover this robot must be stiff enough to reduce as much as possible the structural deflection.

A new computer aided methodology for the design of robots for the construction industry is presented in this paper. This methodology is based on TOROS (Toolbox for Robot Simulation), which allows 3D kinematics CAD, and on ADAMS which allows dynamic analysis and simulation.

\footnotetext{
${ }^{1}$ With the Departamento de Ingeniería. Escuela Politécnica Superior, Universidad Carlos III de Madrid. c/ Butarque, 15, 28911 Leganés (Madrid), Spain.
} 


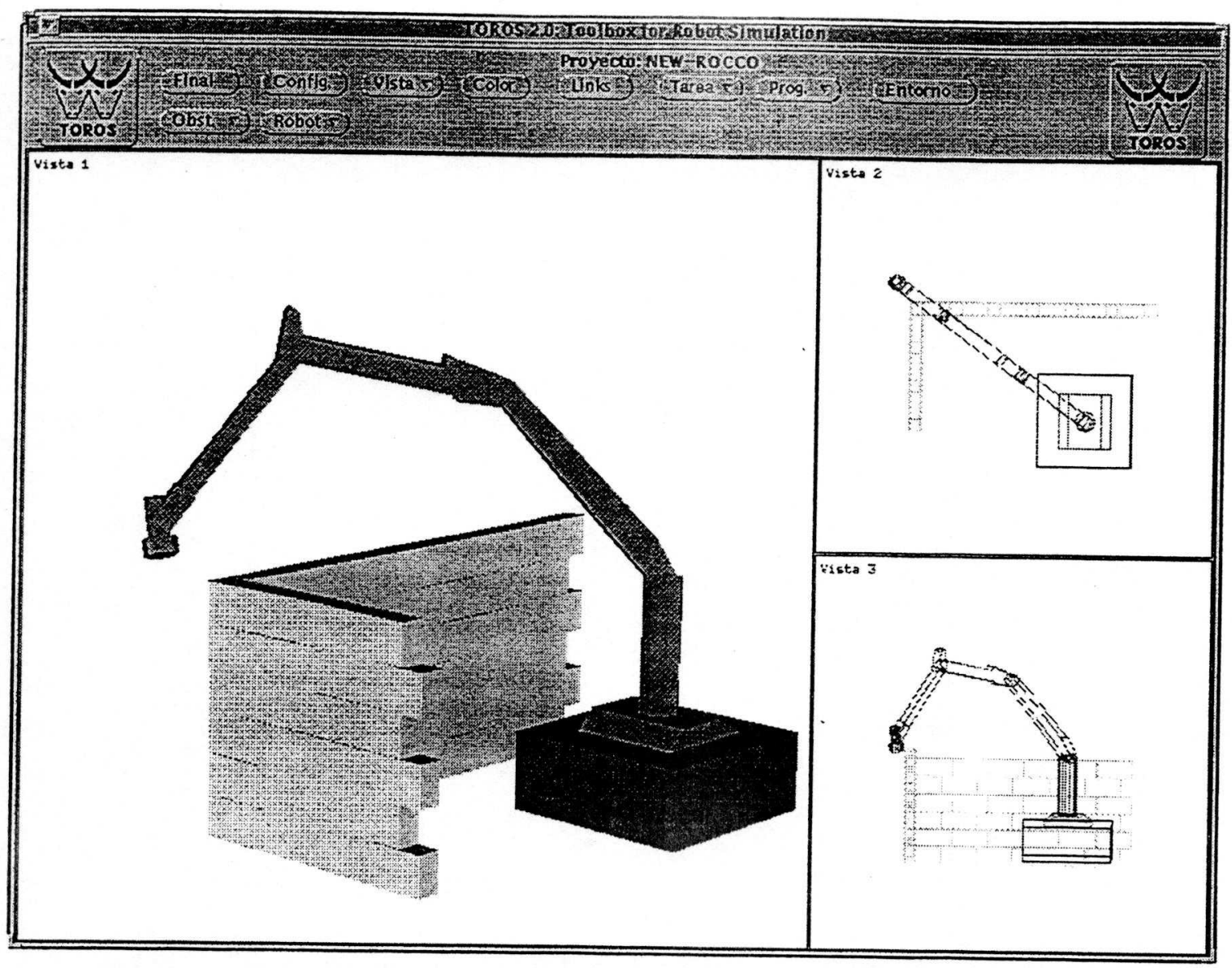

Figure 1. Graphical simulation on TOROS of a construction application

The new methodology has the following steps for robot design:

- Study of the specific construction application and its environment

- Kinematics analysis and design of the robot

- Dynamics analysis and design of the robot structure

- Computation of the robot servo actuators characteristics

The proposed methodology has been already applied and tested for the development of ROCCO robot, which has a range of $8.5 \mathrm{~m}$ and which is able to handle up to 500 $\mathrm{Kg}$. The University Carlos III of Madrid and Polytechnic University of Madrid is also used it for the design of a metallic structure inspection robot ROMA under a common development.

\section{Robot kinematics design}

The kinematics design tool is based on the 3D toolbox for robot simulation TOROS (Fig. 1), which has been developed at the Polytechnic University of Madrid. This tool can be easily used even by non skilled people. This simulator permits to introduce whatever kinematics structure in an easy and friendly way. It is only necessary to create two data files: a) Denavit-Hartenberg parameters of the robot, and b) geometrical representation of the robot elements. Any type of gripper or tool can be added at the robots tip, including the definition of the corresponding TCP. In the same way the environment and the objects to be manipulated are introduced in specific data files. There are two types of the objects: a)passive objects (workpieces), and b)fixed objects (obstacles). An additional facility has been developed to introduce the robot and environment data using the commercial software package AUTOCAD and specific software which permits the automatic definition of the necessary data files for the TOROS simulator.

The main advantages of this tool for the purpose of robot design are:

- Easy change of the kinematics parameters of the robot which helps to establish the number of DOF, length of the links, and kinematics robot configuration. It permits to check the robot configuration in the working environment.

- Powerful drawings facilities, such as 3D and/or 2D views, wire and solid modelling and whatever plane section drawing, etc. This last facility is useful for the purpose of establish the range of joint movements. 


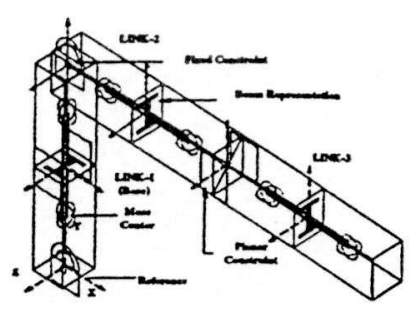

\section{LEVEL-1 STRUCTURE} DESIGN 1
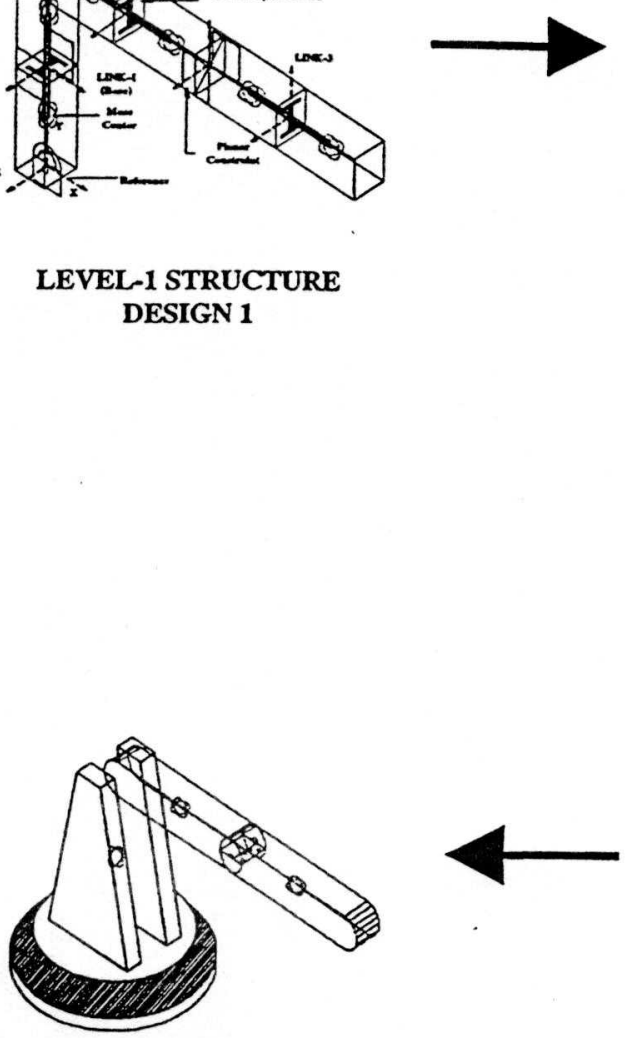

LEVEL-3 SERVO ACTUATORS GENERATION 1

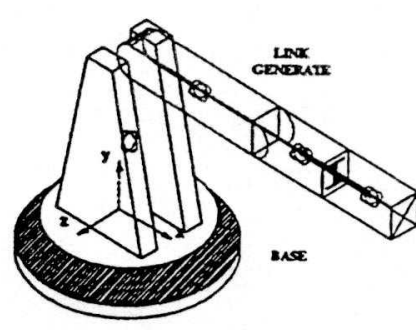

LEVEL-2 ROBOT BASE GENERATION 1
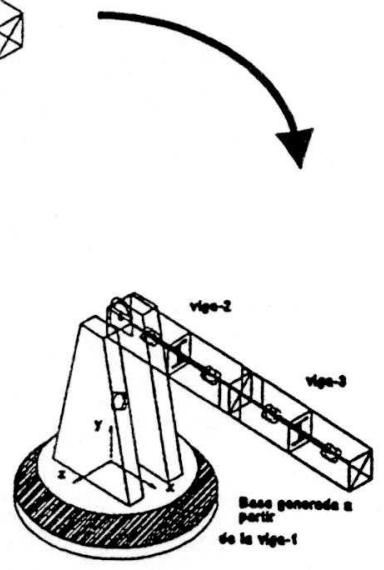

LEVEL-2 LINKS GENERATION 1

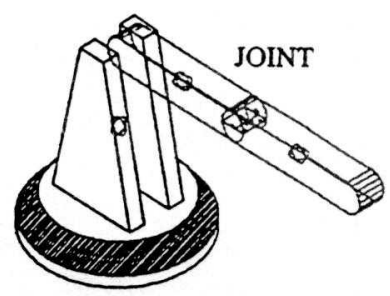

LEVEL-2 CONSTRAINT GENERATION 1

Figure 2. Steps in robot computer aided design

- On the fly collision verification of the robot movements in the introduced environment, including passive and fixed objects.

- Robot programs execution and debugging allowing safe tests without the real robot.

\section{Robot dynamic design}

A set of computational tools for the parametrical design, modelling and simulation of robot dynamic has been developed (Fig. 2). These tools were developed under the 3D dynamics simulation package ADAMS. The kinematics model of the robot (number of DOF, DenavitHartenberg parameters, etc.) developed in previous section is introduced. The additional necessary data are: a) the inertia matrix of the robots parts, b) the robots payload, c) velocity and acceleration requirements, d) types of actuators and its servocontrol, d) robots task including the most useful paths, e) constraints between links, environment, etc.
This tool permits to obtain the dynamical efforts (forces and torques) of the robot joints in an iterative way. These data allows selecting the joint actuators (hydraulic motors and cylinders) and the efforts in the robot gripper that are needed to transport heavy pieces. It also helps to select in an appropriate way the different robot features, such as dimension and stiffness of the robot links, mechanical efforts in the robot base, actuator situation and its maximum torque or forces, etc. With these data it is possible to develop the constructive design of the robots.

\section{Application to the development of a large range robot}

The described methodology has been applied in the development of the ROCCO site assembly robot for wall assembly [9].

The ROCCO robot has a working range of $8.5 \mathrm{~m}$ and a payload capacity of $500 \mathrm{Kg}$. It is placed over a mobile platform that allows it to place in the assembly position on the construction site. 
One of the most critical steps during this development was the computation of the joint dynamical efforts (forces and torques). With this data the selection and situation of the hydraulic actuators (servo cylinders and motors) was performed. This selection has an important influence in the development of the control strategy. Table1 shows resulting torques (for the first five most significant axes) of the ROCCO robot dynamic simulation for different typical paths defined in Table 2.

\begin{tabular}{|c|c|c|c|c|c|}
\hline \multirow{2}{*}{ Joint } & \multicolumn{5}{c|}{ Torques (Nm) } \\
\cline { 2 - 6 } & Path 1 & Path 2 & Path 3 & Path 4 & Path 5 \\
\hline 1 & 67,429 & 44,953 & 26,972 & 53,943 & 53,943 \\
\hline 2 & 196,960 & 154,390 & 120,340 & 171,420 & 95,808 \\
\hline 3 & 115,770 & 89,634 & 68,882 & 100,010 & 47,508 \\
\hline 4 & 56,206 & 43,273 & 32,396 & 48,486 & 19,983 \\
\hline 5 & 8,289 & 6,243 & 4,786 & 7,122 & 2,531 \\
\hline
\end{tabular}

Table 1. Axes torques for the ROCCO robot

\begin{tabular}{|c|c|c|c|c|c|}
\hline \multicolumn{2}{|c|}{ Path 1 } & \multicolumn{1}{c|}{ Path 2 } & \multicolumn{1}{c|}{ Path 3 } & \multicolumn{1}{c|}{ Path 4 } & Path 5 \\
\hline $\begin{array}{c}\text { Angular } \\
\text { velocity } \\
\text { (/sec) }\end{array}$ & 15 & 15 & 15 & 30 & 15 \\
\hline $\begin{array}{c}\text { Time } \\
\Delta \mathrm{t} \\
(\mathrm{msec})\end{array}$ & 200 & 300 & 500 & 500 & 500 \\
\hline $\begin{array}{c}\text { Type of } \\
\text { move- } \\
\text { ment }\end{array}$ & $\begin{array}{c}\text { Simulta } \\
\text { neous }\end{array}$ & $\begin{array}{l}\text { Simulta } \\
\text { neous }\end{array}$ & $\begin{array}{l}\text { Simulta } \\
\text { neous }\end{array}$ & $\begin{array}{l}\text { Simulta } \\
\text { neous }\end{array}$ & $\begin{array}{c}\text { Sequen } \\
\text { tial }\end{array}$ \\
\hline
\end{tabular}

Table 2. Type of robot paths

Other critical step during the design has been the robot configuration. Several configurations such as SCARA or telescopic arms were successively studied and rejected. Finally, an articulated configuration (Fig. 3) was selected.

The block assembly operation is performed in the vertical direction and for this reason two degrees of freedom (DOF) for orientation and three ones for positioning are enough. However, the developed robot is redundant and has six DOF (4 for position and 2 for orientation) in order to increase its obstacle avoidance capacity, dexterity and to allow a good position to transport it by truck to the construction site.

Hydraulic motors are use for the first joint, which moves in the horizontal plane, and for the robot wrist (latter two joints). Hydraulic cylinders move the other axes. All the actuators are controlled by high precision servovalves.

A control strategy based on a fuzzy supervisor has been selected in order to cope with the changing conditions and the high nonlinearities of the system [10]. This supervisor is in charge of adapting the control parameters (controller gains) in real time. Additionally, an external global position sensor (telemeter) is used to correct errors due to static deflections of the robot structure [11].

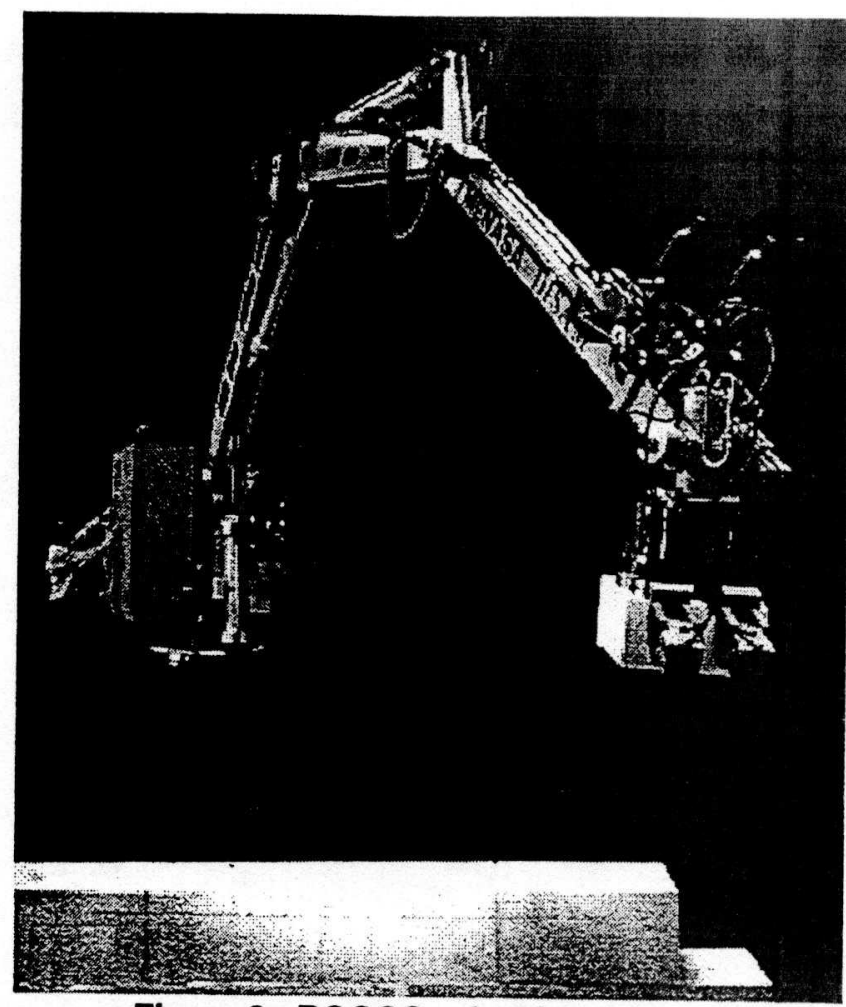

Figure 3. ROCCO robot in construction application

The obtained robot accuracy is $\pm 1 \mathrm{~cm}$, while the repeatability is $\pm 5 \mathrm{~mm}$. The final required position accuracy for the assembly tasks $( \pm 2 \mathrm{~mm}$ ) is achieved by means of a passive compliance device installed on the gripper specially developed for this robot.

The global position sensor is also used to correct minor errors during the robot and blocks pallets placement whit respect to the wall.

\section{Conclusions}

A new methodology of the robot kinematics and dynamics design has been developed. This methodology was successfully applied to the large range construction robot ROCCO and it is being used for new ones. The methodology links the kinematics and dynamics design steps, including the selection of the actuators. This technology permits to decrease the time for the design steps and performed it in an interactive way. Also avoid the possibility of errors during the construction of large range robots. Finally, the cost of the robot development is reduced too.

\section{Acknowledgements}

This works was partially supported by the European ESPRIT III program and the Spanish CICYT program. The authors wish to thanks the contribution of company MENASA in the mechanical ROCCO robot construction. 


\section{References}

[1] C. Balaguer, et al., TOROS: Graphical toolbox for robot simulation, International Workshop on Graphics and Robotics, Dagstuhl (Germany), 1993.

[2] R. Saltarén, Tools for Modelling and parametric design of robots based on multibody dynamical systems, $\mathrm{Ph}$. D. Thesis, Polytechnic University of Madrid, 1996.

[3] C. Balaguer, et al. Site assembly in construction industry by means of a large range advanced robot, $13^{\text {th }}$ ISARC, Tokyo (Japan), 1996.

[4] Y. Miyatake et al., Automation and Robotics in Construction Industry, Proceedings of the International Conference on Robots for Competitive Industries, Brisbane, Australia, 1993.

[5] B. Heinrichs, et al. Position-based impedance control of an industrial hydraulic manipulator, IEEE Control Systems, vol. $17, \mathrm{n}^{\circ} 1,1997$.

[6] Chr. Blume, et al. EMIR - a combination of manipulator and robot for new out-door applications in unstructured environments, IEEE International Conference on Robotics and Automation, Scotts-Dale, Arizona (USA), 1989.
[7] R. Greer, et al. Advances in control systems for construction manipulators, $13^{\text {th }}$ ISARC, Tokyo (Japan), 1996.

[8] A. Warzawski and R. Navon, Survey of building robots, $13^{\text {th }}$ ISARC, Tokyo (Japan), 1996.

[9] E. Gambao, Hydraulic Robot Control. Application to Large Range Robots for the Construction Industry, Ph. D. Thesis, Polytechnic University of Madrid, 1996.

[10] E. Gambao, et al., Fuzzy Gain Scheduling Control Architecture for Large Range Robot, 4 ${ }^{\text {th }}$ IEEE MSCA'96, Chania (Greece), 1996.

[11] E. Gambao, et al., Robot Assembly System for the Construction Process Automation, 1997 IEEE Int. Conference on Robotics and Automation, ICRA'97. Albuquerque, New Mexico, (USA), 1997. 